\title{
Correspondence
}

\section{VALPROIC ACID AND CONGENITAL MALFORMATIONS}

To the Editor:

In their article on congenital malformations associated with maternal use of valproic acid, Huot et al. ' erroneously state that "a possible association with spina bifida was suggested without prospective study", thereby referring to a publication which in fact reported on the results of 13 groups involved in prospective studies of the general outcome of gestational antiepileptic drug exposure. ${ }^{2}$ In that study, 393 pregnancies with any valproate exposure of which 120 with exposure to valproate only, and 1718 with exposure to other antiepileptic drugs, were ascertained and followed prospectively. In the groups exposed to valproate with or without other antiepileptic drugs, five cases of spina bifida and one case of anencephaly was observed. In the subgroup of 120 infants exposed to valproate only, there was one case of anencephaly and two of spina bifida. Therefore, this prospective study confirmed the suspicion raised by retrospective case-comparison studies of data from birth defects registries ${ }^{3}$ in that the actual risk of neural tube defects is increased to $1-2 \%$, which is considerably higher than the risk in the general population and that connected with other anticonvulsant drugs. This may also correct a statement by Huot et al. that "besides the nine cases of spina bifida reported from Lyon by Robert et al., only two of the 37 other children exposed to valproic acid monotherapy were born with this anomaly". Furthermore, they confine their review of valproic acid monotherapy exposures to only those which had any kind of malformation, selected from case-reports and various other types of study. Therefore, calculations about the risk of neural tube defects with valproate monotherapy exposure cannot be done on their data. Huot et al. regarded the study by Nau et al. ${ }^{4}$ and Jäger-Roman et al. ${ }^{5}$ as independent studies, but in fact these two reports come from the Berlin study group and represent data from a possibly overlapping patient group. This Berlin group was one of the participants in our international collaborative study, ${ }^{2}$ and therefore the valproate exposures - including the one case of spina bifida - from the Berlin group are included in collaborative study. ${ }^{2}$ Prevention of valproate induced spina bifida is indeed possible by change of medication before pregnancy, if possible. However, when valproate exposure during pregnancy cannot or has not been avoided, prenatal diagnosis (amniotic fluid analysis and/or ultrasound) with termination of pregnancy in case of positive findings is an option that should be offered. This policy, adopted by the seven Clinical Genetics Centers in The Netherlands, is well accepted by the patients and has thus far resulted in the prevention of at least one case of lumbosacral spina bifida. ${ }^{6}$

D. Lindhout

Department of Clinical Genetics Erasmus Universiteit Rotterdam Rotterdam
1. Huot C, Gauthier M, Lebel M, et al. Congenital malformations associated with maternal use of Valproic acid. Can J Neurol Sci 1987; 14: 290-293.

2. Lindhout D, Schmidt D. In-utero exposure to valproate and neural tube defects. Lancet 1986; i: 1392-1393.

3. Robert E, Rosa F. Valproate and birth defects. Lancet 1983; $2: 1142$.

4. Nau H, Rating D, Koch S, et al. Valproic acid and its metabolites; placental transfer, neonatal pharmacokinetics, transfer via mother's milk and clinical status in neonates of epileptic mothers. J Pharmacol Exp Ther 1981; 219: 768-777.

5. Jäger-Roman, Deichl A, Jakob $S$, et al. Fetal growth, major malformations, and minor anomalies in infants born to women receiving valproic acid. J Pediatr 1986; 108: 997-1004.

6. Wolf $\mathrm{H}$ and Leschot NJ. Prenataal onderzoek naar defecten van de neurale buis bijgebruik van valproinezuur. Ned Tijdschr Geneesk 1985; 129: 1891-1892 (summary in English).

\section{THE PREDICTIVE AND DIAGNOSTIC VALUE OF SIMPLE REACTION TIME AND MOVEMENT TIME IN NORMAL PRESSURE HYDROCEPHALUS}

To the Editor:

Differentiation of Potentially Treatable Dementia due to normal pressure hydrocephalus (NPH) from Alzheimer's disease or artherosclerotic dementia is sometimes difficult because even paraclinical examinations, such as CT scans and radioisotopic cisternograms, are not always conclusive. In 1974, we introduced repeated CSF lumbar punctures for two purposes: 1) as a therapeutic trial in patients who are socially not functional, to help them resume an adequate social life even in the absence of shunting procedures and;2) as a reliable early diagnosis of NPH which might respond to treatment with a shunting procedure.'

In the present study, 17 patients were divided into two groups. The first group was comprised of 10 subjects (age $68.7 \pm 10.9$ ) with the classic NPH syndrome confirmed by the existence of the clinical triad of Hakim and Adams as well as by radioisotopic cisternograms and CT scans. They were subjected to 3 !umbar punctures with withdrawal of $30 \mathrm{ml}$ of CSF at 2 to 3-day intervals. In the second group, 7 patients (age $64.7 \pm 7$ ) with Alzheimer's disease or multi-infarct dementia underwent spinal taps as described above.

In previous studies in our laboratory, we measured simple reaction (RT) and movement time (MT) to visual stimuli with Lafayette apparatus no $63017 .^{2}$ The assessments were carried out according to the method of Hamsher and Benton. ${ }^{3}$ Whereas RT measures the speed of information processing, MT reflects motor performance. This method does not include practice effects as do the majority of other neuropsychological testing procedures. ${ }^{4}$ Visual RT and MT were measured before and after the lumbar punctures. The data were analysed statistically by univaried variance for repeated measures (ANOVA-R).

The mean \pm SD of visual RT in the first group was $487.4 \pm$ 210.9 msec. before vs $370.7 \pm 78.3$ after treatment, whereas in the second group the values were $460.9 \pm 199.6$ vs $506.9 \pm$ 
224.4 respectively. The visual $\mathrm{MT}$ values were respectively $694.2 \pm 396.2$ vs $408.1 \pm 169.3$ (group 1) and $531.9 \pm 348.9$ vs $546.3 \pm 319.5$ (group 2). Because of the high variability of the $\mathrm{SD}$, lagarithmic transformation and subsequent variance analysis were necessary.

The results showed a significant diminution of visual RT in group 1 in the post-trial examination $(\mathrm{F}=13.57, \mathrm{~d} 1=1, \mathrm{p}=$ $.002)$ but no significant changes were noted in group $2(\mathrm{~F}=$ $1.81, \mathrm{~d} l=1, \mathrm{p}=.198$ ). There was also a significant diminution in visual $\mathrm{MT}$ in group $\mathrm{l}(\mathrm{F}=9.38, \mathrm{dl}=1, \mathrm{p}=.008)$ whereas group 2 showed no significant changes $(F=.03, d l=1, p=$ .87).

We therefore conclude that simple RT and MT assessment is a useful method for establishing whether or not repeated withdrawals of CSF by lumbar puncture improve the condition of NPH patients, thus allowing both a precise diagnosis in doubtful cases as well as a good predictive value for eventual shunting procedures.

Luc Marchand Therese Botez Neurology Service Hôtel-Dieu Hospital Montreal, Canada
1. Botez MI, Ethier R, Léveille J, Botez-Marquard T. A syndrome of early recognition of occult hydrocephalus and cerebral atrophy. Quart J Med 1977; 46: 365-380.

2. Botez MI, Elie R, Botez T, et al. Cerebellar atrophy in outpatient epileptics: A neurobiological study. Can J Neurol Sci 1987; 14: 251-252.

3. Hamsher $\mathbf{K}$ de $\mathbf{S}$, Benton $\mathrm{AL}$. The reliability of reaction time determinations. Cortex 1977; 13: 306-310.

4. Ladurner G, Tschinkel M, Klebl H, Lytwin H. Reaction time in cerebrovascular disease. Arch Geront Geriat 1985; 4: 373-379. 